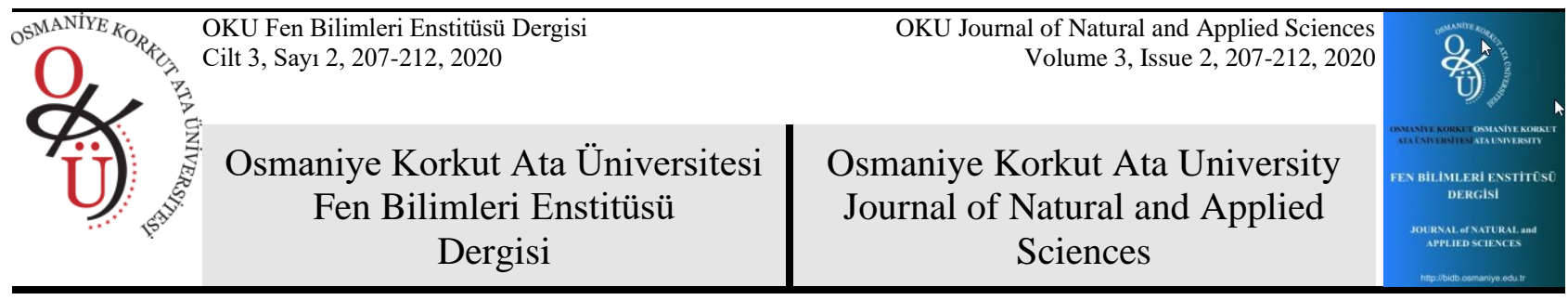

\title{
Balda Hile Tespitinde İzotopik Analiz Uygulamaları
}

\author{
İlkay TÜRKMEN ÖZEN ${ }^{1 *}$ \\ ${ }^{1}$ Gümüşhane Üniversitesi Mühendislik ve Doğa Bilimleri Fakültesi, Gıda Mühendisliği Bölümü, 29000, Gümüşhane \\ ${ }^{1}$ https://orcid.org/0000-0002-0365-0370 \\ *Sorumlu yazar: ilkay-turkmen@ hotmail.com
}

\section{Derleme}

\section{Makale Tarihçesi:}

Gelis tarihi: 14 Kasım 2020

Kabul tarihi:27 Kasim 2020

Online Yayınlanma: 15 Aralık 2020

\section{Anahtar Kelimeler:}

İzotopik analiz

Otantiklik

Bal

IRMS

C3 şeker

${ }^{13} \mathrm{C} /{ }^{12} \mathrm{C}$

\section{ÖZET}

İzotopik analiz uygulamalarının temeli karbon, hidrojen ve oksijen atomlarının izotop oranlarının tespitine dayanır. Bitkilerde izotop atom dağılımının tespitinde yararlanılan en önemli faktör bitkinin hangi fotosentez sistemine dahil olduğu ile ilgilidir. Fotosentez sistemi sınıflandırmasına göre bitkiler C3, C4 ve CAM bitkileri olarak gruplandırılmaktadır. Bitkilerin karbon metabolizmalarının belirlenmesinde $\delta^{13} \mathrm{C}\left({ }^{13} \mathrm{C} /{ }^{12} \mathrm{C}\right)$ değeri standart değer olarak kabul edilir. $\delta^{13} \mathrm{C}$ değerleri C3, C4 ve CAM bitkileri arasında farklılık gösterir ve bu farklılıktan yola çıkarak bir gıdanın gerçekliği/otantikliği veya bir gıdaya başka bir gruptan gida ya da bileşen katılıp katılmadığı tespit edilebilmektedir. Bal da izotopik analiz uygulamaları ile gerçekliği belirlenebilen gıdalardan biridir. Arılar bal üretiminde çoğunlukla C3 fotosentez sistemine dahil olan bitkilerin özlerini kullanmaktadır. Hileli bal yapımında ise şeker kamışı ve mısır gibi $\mathrm{C} 4$ fotosentez sistemini kullanan bitkiler kullanılmaktadır. Şeker pancarı şekeri ilavesi ile yapılan sahte balların belirlenmesinde baldan protein ekstrakte edilir ve $\delta^{13} \mathrm{C}$ değeri belirlenerek bu değer hakiki balın $\delta^{13} \mathrm{C}$ değeri ile karşılaştırılır. Kabul edilen uluslararası limite göre, karşılaştırılan balların $\delta^{13} \mathrm{C}$ değerleri arasındaki fark \%ol'den farklı olmamalıdır. Bu derleme makalesinde izotopik analizler hakkında bilgi verilerek bu yöntemlerin baldaki uygulamaları ile hileli ve gerçek balın tespiti üzerine katkısının açıklanması amaçlanmıştır.

\section{Isotopic Analysis Applications in Honey Adulteration Detection}

\section{Reviews}

\section{Article History}

Received: 14 November 2020

Accepted: 27 November 2020

Published online: 15 December 2020

\section{Keywords:}

Isotopic analysis

Authenticity

Honey

IRMS

C3 sugar

${ }^{13} \mathrm{C} /{ }^{12} \mathrm{C}$

\begin{abstract}
The basis of isotopic analysis applications is based on the determination of the isotope ratios of carbon, hydrogen and oxygen atoms. The most important factor used in determining the isotope atom distribution in plants is related to which photosynthesis system the plant is involved in. Plants are grouped as $\mathrm{C} 3, \mathrm{C} 4$ and CAM plants according to the photosynthesis system classification. $\delta^{13} \mathrm{C}\left({ }^{13} \mathrm{C} /{ }^{12} \mathrm{C}\right)$ value is accepted as a standard in determining the carbon metabolism of plants. There is a difference between the $\delta^{13} \mathrm{C}$ values of $\mathrm{C} 3, \mathrm{C} 4$ and $\mathrm{CAM}$ plants. Utilizing this distinction, addition a food or food component from another group participates in a food, or the authenticity of food can be determined. Honey is one of the foods whose authenticity can be determined by isotopic analysis applications. Honey bees usually use $\mathrm{C} 3$ plant extracts in honey production. In the production of adulterated honey, $\mathrm{C} 4$ plants such as sugarcane and corn are used. Detection of adulterated honey which made with sugar beet sugar added, protein extracted from the honey to detect $\delta^{13} \mathrm{C}$ value and this value is compared with the value of pure honey $\delta^{13} \mathrm{C}$. According to the accepted international limit, the difference between the $\delta^{13} \mathrm{C}$ values of the compared honeys should not differ from \%o 1 . In this review article, it is aimed to explain the application of these methods in honey and their contribution to the detection of adulturated honey by giving information about isotopic analysis.
\end{abstract}


To Cite: Özen İT. Balda Hile Tespitinde İzotopik Analiz Uygulamaları. Osmaniye Korkut Ata Üniversitesi Fen Bilimleri Enstitüsü Dergisi 2020; 3(2): 207-212.

\section{Giriș}

Bal; bitki nektarlarının, bitkilerin canlı kısımlarının salgılarının veya bitkilerin canlı kısımları üzerinde yaşayan bitki emici böceklerin salgılarının bal arısı tarafindan toplandıktan sonra kendine özgü maddelerle birleştirerek değişikliğe uğrattığ 1 , su içeriğini düşürdüğü ve petekte depolayarak olgunlaştırdığı doğal ürün olarak tanımlanmaktadır [1]. Dünyanın hemen her ülkesinde yirmi milyon yıldır üretilen balın Gida Tarım Örgütü (FAO) tarafından düzenlenen ülkelere göre üretim istatistiğinde, Çin'den sonra 2. sirada 103,525 ton bal üretimi ile Türkiye yer almaktadır [2]. Bal, tek bir nektar kaynağından elde ediliyorsa monofloral, farklı nektarların karışımından oluşuyorsa polifloral olmak üzere iki ayrı sinıfa ayrılmaktadır [3]. Balın kimyasal bileşimi ve özellikleri hem botanik hem de coğrafi orijinine bağlı olarak değişiklik göstermektedir. Botanik orijin balın elde edildiği kaynağ göstermekte iken coğrafi orijin ise balın üretildiği menşeini yani coğrafi alanı belirtmektedir.

Arıların bal yaparken yararlandığı bitkiler bölge ve iklim koşullarına göre değişim gösterdiğinden balın kimyasal bileşimi de değişim göstermektedir. Balın kimyasal içeriği yaklaşık $\% 80$ şeker, $\% 17$ su, $\% 3$ ise enzimler ve mineral, vitamin, organik asitler, aminoasitler ve aroma maddeleri vb. gibi bileşiklerden oluşmaktadır [4].

Bal besin değeri açısından en değerli ve yüzyıllar boyunca üretilen en eski gidalardan biridir. Balın gıda, ilaç ve dini törenlerde kullanımı çok eski medeniyetlere kadar dayanmaktadır. Balda kalite arttıkça fiyat oldukça artmakta bu da kaliteli ballara daha düşük kalitede balların karıştırılması ve kaliteli olanın adı ile pazarlanması şeklinde hileli bal üretiminin yaygın olarak yapılmasını ortaya çıkarmaktadır. Bu şekilde hem tüketiciler aldatılmakta hem de haksız kazanca neden olunmaktadır.

\section{Balda Yapılan Yaygın Hileler}

Balda direkt, indirekt ve karışım olmak üzere başlıca 3 tipte hile yapılmaktadır. Direkt ve indirekt tipte hilelerin yapilmasında kullanılan tağşiş maddeleri ikiye ayrılmaktadır. Birinci grup; nişasta şurubu (yüksek fruktozlu misır şurubu, mısır şurubu, şeker kamışı şurubu, pirinç şurubu, manyok nişastasından elde edilen şurup), invert şurup (şeker kamışı şurubu ve şeker pancarı şurubu) ve diğerleri (yüksek fruktozlu inülin şurubu) olarak ayrilırken ikinci grupta ise yüksek fruktozlu misır şurubu, sakaroz şurubu ve arı beslemede kullanılan şurup yer almaktadır. Pahalı balların ucuz ballarla karıştırılması (örneğin akasya balı ile kolza balının, Melipona fovasa balarıs1 ile Apis mellifera balarısı ballarının karşılaştırılması) ise karışım şeklinde yapılan tağşiş sınıfını oluşturmaktadır. Bunlar içerisinde en yaygın kullanılanlar ise yüksek fruktozlu mısır şurubu, mısır şurubu, invert şeker şurubu ve şeker kamışı şurubudur [5].

\section{Balda Yapılan Hilelerin Tespitinde Kullanılan Yöntemler}

Balda yapılan tağşişin tespit edilmesinde melissopalinolojik, duyusal analiz, şeker profili, amino asit profili, enzim aktiviteleri, hidroksi metil furfural ve prolin değerleri ölçümlerinden yararlanılmakla birlikte bu testler tağşş̧̧inin belirlenmesinde zaman alıcı ve sadece basit hilelerin tespiti için yeterli olabilmektedir [6].

Günümüzde bala şeker şurubu ilavesi şeklinde yapılan hilelerin tespiti için birçok metot geliştirilmiştir. $\mathrm{Bu}$ metotlardan en fazla uygulananlar Yüksek Performanslı Siv1 Spektrofotometresi (HPLC) [7], Yakın Kızılötesi Spektroskopisi (NIR) [8], Gaz KromatografiKütle Spektrometresi (GC-MS) [9], Orta Dalga Boylu Kızılötesi Spektrokopisi (MIR) [10], Diferansiyel Taramalı Kalorimetresi (DSC) [11], vurgulu amperometrik detektörlü yüksek performans anyon değişim kromatografisi [12], Raman spektroskopisi [13], Yüksek Çözünürlüklü Manyetik Rezonans Spektroskopisi (HR-NMR) [14] ve İzotop Oranı Kütle Spektrometresi (IRMS) [15,16]'dir. Bu metotlar arasinda C4 şeker tespitinde kullanılan en yaygın metot ise Stabil Karbon İzotop Oran Analizi (SCIRA)'dir [17].

\section{4. İzotopik Analiz Uygulamaları}

Atom, dünya üzerindeki tüm maddeleri oluşturan en temel yapıtaşıdır. Atomlar çekirdeklerinde bulunan nötron ve protonlar ile çekirdeklerinin etrafındaki yörüngede bulunan elektronlardan meydana gelmektedir. İzotop atom; aynı sayıda 
proton ve elektrona yani aynı atom numarasina sahip olmalarına karşın farklı sayıda nötrona sahip olan atomlar olarak tanımlanmaktadır. Bazı elementler doğada tek bir izotop halinde bulunur fakat doğadaki elementlerin birçoğunun birden fazla izotopu bulunmaktadır. Biyolojik yapılar esas olarak $\mathrm{C}, \mathrm{O}, \mathrm{H}$ ve $\mathrm{N}$ atomlarından oluşmaktadır. Bilindiği gibi hidrojenin $\mathrm{H}$ ve $\mathrm{D}$, karbonun ${ }^{12} \mathrm{C}$ ve ${ }^{13} \mathrm{C}$ olmak üzere iki ve oksijenin ise ${ }^{16} \mathrm{O},{ }^{17} \mathrm{O}$ ve ${ }^{18} \mathrm{O}$ olmak üzere üç izotop atomu bulunmaktadır. Bunlardan doğada yaygın olarak bulunanlar $\mathrm{H},{ }^{12} \mathrm{C}$ ve ${ }^{16} \mathrm{O}$ 'dir [18].

Biyoelementlerin doğadaki dağılımı ve fraksiyonlaşması su döngüsüne bağlıdır. Suyun buharlaşması sırasında hafif izotopların buharlaşması ağır izotoplara göre önceliklidir. Su döngüsüne bağlı fraksiyonlaşma sonucunda yağışın izotop dağılımı o bölgeye özgü belirli bir coğrafi dağılım/profil göstermektedir. Topraktan bitkinin yaprak saplarına kadar ulaşan su takip ettiği yolda, o bölgedeki yağışın izotop dağılımını sahiptir [18]. Karbon izotoplarının doğal varyasyonlar1, bitkilerin farkl1 fotosentez sistemlerini kullanmaları ve bölgeye özgü su döngüsü etkenlerinden etkilenmesi nedeniyle ortaya çıkmaktadır.

Bitkiler atmosferden $1 \mathrm{~mol} \mathrm{CO}_{2}$ alabilmek için gözeneklerinden yaklaşık olarak $1000 \mathrm{~mol} \mathrm{su}$ vermektedirler. Yani önemli miktarda su kaybetmektedirler. Bitkilerde ve bitkisel kaynaklı gıdalarda izotop dağılımını belirleyen en önemli faktör bitkinin hangi fotosentez sistemi grubuna dahil olduğu ile ilgilidir. Buna göre bitkiler, C3 (Calvin-Benson döngüsü), C4 (Crassulacean asit metabolizmasi) ve CAM (Hatch-Slack döngüsü) bitkileri olarak gruplandırılmaktadır. Bitkilerde en çok 3 karbonlu fotosentez sistemi görülür. $\mathrm{Bu}$ oranlar Tablo 1'de verilmiştir. Bu sistemde ilk oluşan bileşik 3 karbonlu olduğu için bu fotosentez sistemine 3 karbonlu sistem ve bu bitkilere de $\mathrm{C} 3$ bitkileri adı verilmektedir. Yani bitkilerin büyük çoğunluğu aldığ $\quad \mathrm{CO}_{2}{ }^{\prime} \mathrm{i} \quad 3$ karbonlu bir yapıya bağlamaktadır. Bu bitkilere örnek olarak şekerpancarı, buğday, arpa, pamuk, yonca, korunga vb. bitkiler verilebilir [19, 20, 21].

Bazı bitkiler ise fotosentez sisteminde ilk olarak 4 karbonlu bileşik oluşturduğu yani $\mathrm{CO}_{2}$ 'i kendi karbon zincirlerindeki 4 atomlu bileşiklere bağladıkları için 4 karbonlu fotosentez sistemine dahil olup C4 bitkileri olarak adlandırılmaktadır. $\mathrm{Bu}$ gruptaki bitkiler genellikle dünyanın sıcak bölgelerinde yetişmektedir [22]. Buna göre sitrus, üzüm, elma vb, gibi meyveler ile misir, şekerkamışı, sorgum, sudan otu, darı vb. gibi bitkiler $\mathrm{C} 4$ bitkileri grubuna girmektedir [23].

Fotosentez sistemi olarak Crassulacea (et yaprak) bitkisinde görülen Krasulasyon Asit Metabolizması (CAM) olarak adlandırılan üçüncü $\mathrm{CO}_{2}$ özümleme sistemine sahip bitkiler ise CAM bitkileri olarak adlandırılmaktadır. Bu grupta ise daha çok etli yaprak ve gövdeye sahip ananas, kaktüs, agavel ve dikenli armut gibi bitkiler yer almaktadır [23]. Bu gruptaki bitkiler düşük transprasyonun yaşamsal düzeyde gerekli olduğu kurak koşullara adaptasyon göstermişlerdir. Düşük nem koşulları altında bu bitkiler $\mathrm{CO}_{2}$ absorbe etmek için gece stomalarını açar, gündüz kapatırlar. $\mathrm{Bu}$ yolla bitkinin transprasyon yükü azalmış olur [22].

Bitkilerin $\mathrm{C}$ metabolizmalarının tespitinde $\delta^{13} \mathrm{C}$ değeri yani ${ }^{13} \mathrm{C} /{ }^{12} \mathrm{C}$ oranı standart değer olarak kabul edilir ve \%o olarak gösterilmektedir [24].

Tablo 1. C3, C4 ve CAM bitki türlerinin $\delta^{13} \mathrm{C}$ değerleri

\begin{tabular}{llll}
\hline $\begin{array}{l}\text { Bitki } \\
\text { Türü }\end{array}$ & C3 & C4 & CAM \\
\hline$\delta^{13} \mathrm{C}$ & $\delta \%$-22 ile & $\delta \%$ - 10 & $\delta \%$ - 11 \\
Değeri & $\delta \%$-33 & ile $\delta \%$-20 & ile $\delta \%$ - 13,5 \\
\hline
\end{tabular}

Tablo 1'de görüldüğü üzere C3, C4 ve CAM bitki türlerinin $\delta^{13} \mathrm{C}$ değerleri arasında farklılıklar söz konusudur [25]. Bu farkl111ktan yararlanarak bir gıdaya başka gruptan bir gıdanın veya bileşenin katılıp katılmadığı ya da gıdanın gerçekliği yani üretiminde hile/tağşiş yapılıp yapılmadığı belirlenebilmektedir. Aynı zamanda, izotop oranından yola çıkılarak gıdanın bitki çeşidi, üretim yılı ve coğrafi orijini gibi tanımlayıcı bilgileri de belirlenebilmektedir. K1saca bir gıdadaki elementlerin izotop oranları yardımı ile o gıdanın coğrafi orijini, üretiminde su, şeker vb. katkılarla hile yapılıp yapılmadığı gibi birçok tanımlayıcı özelliği belirlenebilmektedir.

Günümüzde hileli üretim yapılan gidaların başında gelenlerden biri de baldır. Bunun nedeni ise bal fiyatlarının balın kalitesi ve menşei ile doğrudan ilişkili olmasıdır.

Balda yapılan sahteciliğin en basiti düşük nem içerikli ballara su ilave edilmesi şeklinde uygulanmaktadır. Diğer yaygın yapılan hileler ise yüksek fruktozlu mısır şurupları ile şekerkamışı ve şekerpancarından elde edilen sakarozun asitle 
inversiyonu ile üretilen şeker şuruplarının bala ilave edilmesi şeklindedir. Balarıları bal üretiminde genellikle C3 bitki özlerini kullanmaktadır. Sahte bal üretiminde ise şeker kamışı ve mısır vb. gibi $\mathrm{C} 4$ bitkileri kullanılmaktadır. Şekerpancarı şekeri katkısı ile yapılan hileli balların tespiti baldan protein ekstrakte edilerek $\delta^{13} \mathrm{C}$ değeri tespit edilmesi ve bu değerin saf balın $\delta^{13} \mathrm{C}$ değeri ile karşılaştırılması şeklinde yapılmaktadır (Tablo 2). Balda geleneksel laboratuvar yöntemleriyle tağşişin tespit edilmesi çok zor olduğundan bal ile protein fraksiyonu arasındaki stabil karbon izotop oranındaki $\left({ }^{13} \mathrm{C} /{ }^{12} \mathrm{C}=\%\right.$ ) farklılık balın saf olup olmamasının belirlenmesinde kalitatif ve kantitatif bir gösterge olarak kabul edilmektedir [26]. Belirlenen uluslararası limite göre, doğal ballardan ekstrakte edilen protein ile saf balın değerleri arasındaki farkın \%ol'den farklı olmamas1 gereklidir [3, 27, 28].

Tablo 2. Saf baldaki \%C4 şeker katkısının bal ve protein $\delta \%$ değerlerine yansıması ve hesaplanan $\% \mathrm{C} 4$ şeker değeri [25]

\begin{tabular}{cccc}
\hline $\begin{array}{c}\% \mathrm{C} 4 \\
\text { şeker }\end{array}$ & Bal $(\delta \%)$ & Protein $(\delta \%)$ & $\begin{array}{c}\text { Hesaplanan } \\
\% \mathrm{C} 4 \text { şeker }\end{array}$ \\
\hline 0 & $-27,5 \pm 0,12$ & $-26,9 \pm 0,16$ & 0 \\
0,5 & $-26,8 \pm 0,20$ & $-26,9 \pm 0,16$ & 0,6 \\
1,0 & $-26,7 \pm 0,17$ & $-26,9 \pm 0,16$ & 0,9 \\
2,0 & $-26,6 \pm 0,19$ & $-26,9 \pm 0,16$ & 2,0 \\
5,0 & $-26,1 \pm 0,28$ & $-26,9 \pm 0,16$ & 5,2 \\
10 & $-25,2 \pm 0,34$ & $-26,9 \pm 0,16$ & 10,9 \\
15 & $-24,5 \pm 0,27$ & $-26,9 \pm 0,16$ & 15,8 \\
20 & $-23,7 \pm 0,36$ & $-26,9 \pm 0,16$ & 20,6 \\
50 & $-19,2 \pm 0,44$ & $-26,9 \pm 0,16$ & 50,5 \\
70 & $-16,1 \pm 0,40$ & $-26,9 \pm 0,16$ & 70,4 \\
\hline
\end{tabular}

Yöntemin yarayışlılığının belirlenmesi amacıyla Türkiye' de 13 farklı marka bal numunesinde çalışıllmış ve çalışma sonucunda $\quad \delta^{13} \mathrm{C}$ değerlerinin $\%$ o-12,87 $\pm 0,01$ ile $\%$ - $25,56 \pm 0,08$ ve protein $\delta \%$ değerlerinin $\%$ - $23,77 \pm 0,09$ ile $\%$ o $-25,98 \pm 0,06$ arasında değiştiği belirlenmiştir [29].

Yapılan başka bir çalışmada 12 adet saf balın $\delta^{13} \mathrm{C}$ değeri ortalama $\%$ - $25,73 \pm 0,29$ ve protein $\delta \%$ o değeri ise ortalama $\%-25,52 \pm 0,27$ olarak belirlenmiştir. Yapılan çalışmada saf ballara sakkaroz şurubu, yüksek fruktozlu mısır şurubu ve glukoz şurubu katkısı arttıkça ters orantılı olarak örneklerin $\delta^{13} \mathrm{C}$ değerleri ile protein $\delta \%$ değerlerinin azaldığı belirlenmiştir. [30].

Arıların bal yaparken kullandığı nektarlar ile şeker pancarı C3 bitki grubunda iken misır ve şeker kamışı bitkileri $\mathrm{C} 4$ bitki grubundadır. $\mathrm{Bu}$ farklı1ıktan yararlanılarak balda şeker kamış1 şekeri ve mısır şurubu gibi şeker şurupları katkısı izotopik bileşim analizleri ile kolaylıkla belirlenebilmektedir [31]. Araştırmacılar balda yüksek fruktozlu şeker şurubu (HFCS) konsantrasyonu arttıkça $\mathrm{C} 4$ şeker içeriği değerinin arttı̆̆ını bildirmiştir [15].

\section{Sonuç}

Son yıllarda balda yapılan hilelerin en büyük kısmını şeker şurubu ile besleme, bala invert şeker şurubu, yüksek fruktozlu misır şurubu, glikoz şurubu gibi şeker şurubu katkısı oluşturmaktadır. Hakiki bala şeker kamışı, mısır gibi C4 bitkilerinin şurubu katkısı $\delta^{13} \mathrm{C}$ değerinin belirlenmesi ile tespit edilebilmektir. Son y1llarda g1da otantikliğinin belirlenmesi amacıyla gidaların bileşiminde bulunan farklı bileşenlerin kararlı izotop oranlarından yararlanılması yaygın olarak yararlanılan bir yöntemdir. Baldaki hilelerin belirlenmesi ile tüketicinin hem sağlığ korunmakta hem haksı kazancin önüne geçilebilmekte hem de sahteciliğin önüne geçmek mümkün olmaktadır.

\section{Kaynakça}

[1] TGK, Türk Gida Kodeksi: Bal Tebliği. Resmi Gazete, 27 Temmuz 2012-28366. Tebliğ No: 2012/58, 2012.

[2] FAO, Food and Agricultural Commodities Production., Honey. http://www.fao.org/faostat/en/\#data/QL, 2017. (Erişim tarihi: 11.11.2020).

[3] Chen CT., Chen BY., Nai YS., Chang YM., Chen KH., Chen YW. Novel inspection of sugar residue and origin in honey based on the $13 \mathrm{C} / 12 \mathrm{C}$ isotopic ratio and protein content, Journal of Food and Drug Analysis 2019; 27(1): 175-183.

[4] Crane E. A Book of Honey, Oxford University Press, Newyork, 1980. 
[5] Se KW., Wahab RA., Syed Yaacob SN., Ghoshal SK. Detection techniques for adulterants in honey: Challenges and recent trends, Journal of Food Composition and Analysis 2019; 80, 16-32.

[6] Elflein L., Raezke KP. Improved detection of honey adulteration by measuring differences between $13 \mathrm{C} / 12 \mathrm{C}$ stable carbon isotope ratios of protein and sugar compounds with a combination of elemental analyzer - isotope ratio mass spectrometry and liquid chromatography - isotope ratio mass spectrometry $(\delta \quad$ 13C-EA/LC-IRMS $)$. Apidologie 2008; 39(5): 574-587.

[7] Cotte JF., Casabianca H., Chardon S., Heritier JL., Grenier-Loustalot MF. Application of carbohydrate analysis to verify honey authenticity. J. Chromatogr. A 2003; 1021, 145-155.

[8] Gok S., Severcan M., Goormaghtigh E., Kandemir I., Severcan F. Differentiation of Anatolian honey samples from different botanical origins by ATR-FTIR spectroscopy using multivariate analysis, Food Chemistry 2015; 170, 234-240.

[9] Ruiz-Matute AI., Soria AC., Martinez-Castro I., Sanz ML. New methodology based on GCMS to detect honey adulteration with commercial syrups, J. Agric. Food Chemistry 2007; 55, 7264-7269.

[10] Sivakesava S., Irudarayaj J. Classification of simple and complex sugar adulterants in honey by mid-infrared spectroscopy, Int. J. Food Sci. Technology 2002; 37, 351-360.

[11] Cordella C., Antinelli JF., Aurıeres C., Faucon JP., Carbol-Bass DC., Sbirrazzuoli N. Use of differential scanning calorimetry (DSC) as a new technique for detection of adulteration in honeys. 1. Study of adulteration effect on honey thermal behavior, J. Agric. Food Chemistry 2002; 50, 203-208.

[12] Morales V., Corzo N., Sanz ML. HPAECPAD oligosaccharide analysis to detect adulterations of honey with sugar syrups, Food Chemistry 2008; 107, 922-928.

[13] Li S., Shan Y., Zhu X., Zhang X., Ling G. Detection of honey adulteration by high fructose corn syrup and maltose syrup using
Raman spectroscopy, J. Food Compos. Anal 2012; 28, 69-74.

[14] Bertelli D., Lolli M., Papotti G., Bortolotti L., Serra G., Plessi M. Detection of honey adulteration by sugar syrups using onedimensional and 461 two-dimensional highresolution nuclear magnetic resonance, $\mathrm{J}$. Agric. Food Chemistry 2010; 58, 8495-8501.

[15] Cinar SB., Eksi A., Coskun İ. Carbon isotope ratio $(13 \mathrm{C} / 12 \mathrm{C})$ of pine honey and detection of HFCS adulteration, Food Chemistry 2014, 157, 10-13.

[16] Guler A., Kocaokutgen H., Garipoglu AV., Onder H., Ekinci D., Biyik S. Detection of adulterated honey produced by honeybee (Apis mellifera L.) colonies fed with different levels of commercial industrial sugar (C3 and $\mathrm{C} 4$ plants) syrups by the carbon isotope ratio analysis, Food Chemistry 2014; 155, 155-160.

[17] Rogers KM., Sim M., Stewart S., Phillips A., Cooper J., Douance C., Pyne R., Rogers P. Investigating C-4 sugar contamination of Manuka honey and other New Zealand honey varieties using carbon isotopes, J. Agric. Food Chemistry 2014, 62, 2605-2614.

[18] Turkmen I., EKSI A. Gıda analitiğinde izotopik yöntemler. Dünya Gıda 2010; 11, 6874.

[19] Kacar B. Bitki Fizyolojisi. A.Ü.Z.F. Toprak Bölümü, Yayın No:1447, Ders kitabı:427, Ankara, 1996.

[20] Çelik N. Ürün Fizyolojisi, Uludağ Üniversitesi Ders Notları, No:79, Bursa, 1998.

[21] Aydemir, O., İnce, F. Bitki Besleme, 653 s, Diyarbakır, 1988.

[22] Türk M., Çelik N. CO2 Özümlemesinde C-3 ve C-4 Tipi Bitkilerde Fotosentez-Solunum Denge Noktalarının Belirlenmesi. Süleyman Demirel Üniversitesi Fen Bilimleri Enstitüsü Dergisi 2006; 10-1,48-51.

[23] Osmond CB. Crassulacean acid metabolism: A curiosity in context. Ann.Rev. Plant Physiol 1978; 29, 379-414.

[24] Pissinatto L., Martinelli LA., Victoria RL., de Camargo PB. Stable carbon isotopic analysis and the botanical origin of ethanol in 
Brazilian brandies, Food Research International 1999; 32, 665-668.

[25] Padovan GJ., Rodriques LP., Leme IA., Jong DD., Marchini, JS. Presence of C4 sugars in honey samples detected by the carbon isotope ratio measured by IRMS, Eurasion Journal of Analytical Chemistry 2007; 2(3): 134-141.

[26] Padovan GJ., De Jong D., Rodrigues LP., Marchini JS. Detection of adulteration of commercial honey samples by the $13 \mathrm{C} / 12 \mathrm{C}$ isotopic ratio, Food Chemistry 2003; 82(4): 633-636.

[27] Çınar, S. Türk çam balının analitik özellikleri. Doktora tezi. Ankara Üniversitesi Fen Bilimleri Enstitüsü Gıda Mühendisliği Bölümü. 90s., 2010.

[28] White JW., Winters K. Honey protein as internal standard for stable carbon issotope ratio detection of adulteration of honey, Journal of the Association of Official Analytical Chemists 1987; 72, 907-911.

[29] Cengiz MF., Durak MZ., Ozturk M. In-house validation for the determination of honey adulteration with plant sugars (C4) by Isotope Ratio Mass Spectrometry (IR-MS), LWT Food Science and Technology 2014; 57(1): 915.

[30] Tosun M. Detection of adulteration in honey samples added various sugar syrups with $13 \mathrm{C} / 12 \mathrm{C}$ isotope ratio analysis method, Food Chemistry 2013; 138, 1629-1632.

[31] Dong H., Luo D., Xian Y., Luo H., Guo X., Li C., and Zhao M. Adulteration identification of commercial honeys with $\mathrm{C}-4$ sugar content of negative values by elemental analyzer (ea) and Liquid Chromatography (LC) coupled to an isotope ratio mass spectrometer (IRMS), J. Agric. Food Chemistry 2016; 64, 16, 32583265 . 